returned to Chicago, where he worked with the wellknown sugar chemist, J. U. Nef, and where he took the degree of Ph.D. in 1909. In the following year he joined the staff of the Carnegie Institution's Desert Laboratory in Tucson, Arizona, where he remained for ten years. During this period he published a number of papers which established his reputation as an original and critical investigator. Among his more important publications of this period may be mentioned those dealing with the mechanism of photosynthesis. At that time the theory that formaldehyde was an intermediate product in photosynthesis was very largely accepted. Spoehr, on repeating under properly controlled conditions the experiments which were supposed to provide the evidence for this theory, was unable to find the slightest indication of formaldehyde production, and Spoehr's work was no doubt largely responsible for the ultimate abandonment of that theory. Perhaps the most important of Spoehr's publications during his time at Tucson was his monograph "The Carbohydrate Economy of the Cacti", published by the Carnegie Institution in 1919.

In 1920 Spoehr moved to the Carnegie Institution's Coastal Laboratory at Carmel, California, followed in 1929 by a move to Stanford University, which in that year took over the housing of the Division (now the Department) of Plant Biology which had been created in the previous year with Dr. Spoehr as its first chairman. While at Carmel, among other publications, he produced two of particular importance. One of these, jointly with J. M. McGee, was "Studies in Plant Respiration and Photosynthesis", published by the Carnegie Institution in 1923, the other his well-known book on photosynthesis published in 1926.

For a short time in 1930-31 Dr. Spoehr was director of the Natural Sciences Division of the Rockefeller Foundation in New York; but in the latter year he returned to Stanford to resume the chairmanship of the Division of Plant Biology. $\mathrm{He}$ retired officially in 1950 but continued thereafter to work in the laboratory that he had directed for so long.

Throughout his life in the Division of Plant Biology Dr. Spoehr's main scientific interests continued to lie in photosynthesis and related matters. Particular mention may be made of his successfully bringing to maturity albino maize plants, while in later years he was much interested in the question of applying the results of research in photosynthesis to increasing the food supply of the world. This led to the idea of the culture of algae on a large scale for the use of food, and by 1947 the possibility of cultivating Chlorella on a large scale for this purpose was taken seriously and a preliminary analysis of the problems involved was prepared by Spoehr and H. A. Milner and published in the Carnegie Institution Year Book for 1948. Although preliminary work on the subject at Stanford Research Institution was ended in 1950, it has been continued elsewhere, and the recent (1953) Carnegie Institution Publication on "Algal Culture", edited by J. S. Burlew, indicates in no uncertain way that further investigation on the problem is proceeding vigorously.

During the Second World War the laboratory of which Dr. Spoehr had charge concentrated on the study of antibiotics from chlorophyll-containing organisms.

As well as by his direct contributions to plant physiological research and literature, Dr. Spoehr served the cause of science in other ways. He was a member of the board of directors of the Forest Genetics Research Foundation, a member of the scientific committee of the Board of Managers of the New York Botanical Garden, a trustee of the California Section of the American Chemical Society, a member of the executive board of the Save-theRedwoods League and for a time chairman of the editorial board of Annual Reviews, Inc. He was a member of the American Philosophical Society, the American Academy of Arts and Sciences, an honorary member of the Linnean Society of London and the Deutsche botanischen Gesellschaft of Berlin. He was awarded the honorary degree of doctor of science of the University of Chicago and he received from the same University one of its Distinguished Alumni Awards in 1943.

Dr. Spoehr is survived by his widow, a son Dr. Alexander Spoehr, the anthropologist and director of the Bernice P. Bishop Museum in Honolulu, a daughter, his mother and a brother.

In preparing this notice of Dr. Spoehr I have been greatly helped by information provided by Dr. J. H. C. Smith and Dr. C. S. French, the present director of the Department of Plant Biology of the Carnegie Institution of Washington.

\section{WALTER StILES}

\section{Dr. A. M. Turing, O.B.E., F.R.S.}

Atan TuRING was born on June 23, 1912, and was educated at Sherborne and King's College, Cambridge. $\mathrm{He}$ was made a Fellow of King's in 1934; he submitted his fellowship dissertation-a version of the central limit theorem for the normal distribution-four months after being placed as Wrangler in the Mathematical Tripos. During his first years of research he worked on a number of subjects, including the theory of numbers and quantum mechanics, and started to build a machine for computing the Riemann $\zeta$-function, cutting the gears for it himself. His interest in computing led him to consider just what sort of processes could be carried out by a machine: he described a 'universal' machine, which, when supplied with suitable instructions, would imitate the behaviour of any other; he was thus able to give a precise definition of 'computable', and to show that there are mathematical problems the solutions of which are not computable in this sense. The paper which contains these results is typical of Turing's methods : starting from first principles, and using concrete illustrations, he builds up a general and abstract argument. Many years later he used an elaboration of the same ideas to prove the unsolvability of the word problem in semi-groups with cancellation.

In 1936 he went to Princeton for two years; he worked on group theory and logic, receiving his Ph.D. for a dissertation on "Ordinal Logies". In this he showed that when transfinite induction is used in logic for proofs and definitions, it is not the ordinal up to which induction runs that has significance, but rather the particular way in which that ordinal is described.

$\mathrm{He}$ was awarded the O.B.E. for the work he did during the War, and after it he was invited by the National Physical Laboratory to direct the design of an electronic digital computor (which he christened "The Automatic Computing Engine"). Although the theoretical aspects of its design were his chief concern, he was also keenly interested in its electronics; and while the final construction was in progress 
he turned to long-term problems, considering how machines might be made to learn by trial and error and the ways in which they could be compared with human brains.

In 1949 he was made deputy director of the Computing Laboratory at the University of Manchester, where work on an electronic computor had just started. He was elected Fellow of the Royal Society in 1951. His last work was a mathematical theory of morphogenesis; the main idea was to show how an originally uniform distribution of interacting substances may, as a result of diffusion, develop a strongly marked pattern. He had already published a version of the theory for distributions around a ring, and was at work on the case of a cylindor; using the machine to solve the appropriate differential equations, he was hoping to be able to exhibit the spiral patterns based on the Fibonaci series which are so frequently found in plants.

The marks of Turing's genius were his originality, his ability to control abstract thought by concrete illustration, and his preference for always working things out for himself. The freshness of his mind, his love of inquiry, and his relish for the comic, made him a lively and stimulating companion.

R. O. GANDY

\section{Prof. C. R. S. Tenniswood}

Charles Robert Sidney Tenniswood, professor of chemistry in Makerere College, University College of East Africa, died on May 22, following an accident in which his car skidded in the grounds of the College. At the time of his death, he was forty-seven and had been head of the Makerere Department of Chemistry for some nine years.

Charles Tenniswood graduated from King's (then Armstrong) College in the University of Durham with first-class honours in chemistry in 1927, being awarded the Freire-Morreco Medal and Prize for experimental work in the final year. The following year he was placed in the first division for the diploma in "theory and practice of teaching before going on to three years of postgraduate research in organic chemistry under Prof. S. R. Clemo. His M.Sc. was awarded for a thesis entitled "Studies in the Synthesis of BridgedRing Compounds of the Quinuclidine 'Type", and he published papers on alkyl derivatives of ethyl malonate and ethyl cyanoacetate and on the lupin alkaloids.

Leaving the University of Durham in 1932, he was appointed head of the Chemistry Department of the Wandsworth Technical Institute, London, and then started a career of teaching which, except for the war years, was to last until his death. During 194144 he was seconded to the Ministry of Supply for work in the field of projectile development.

As a result of the De la Warr Commission in 1937, Makerere College, at Kampala in Uganda, had been planned for development to a university college serving all the territories of British East Africa; but the implementation of these proposals was delayed by the War. When Tenniswood arrived at the beginning of 1945, the level of teaching was of school standard and the teaching facilities consisted of one small and poorly equipped laboratory. At the time of his death nine years later, he had seen his first batch of degree students successful in their London B.Sc. Examination and had brought almost to completion the first of the new laboratories, which are giving East African undergraduates facilities in chemistry quite as good as they could enjoy in a
British university. It was natural that senior members of the staff should have to bear a heavy burden of administration in the early days of a university. Tenniswood made invaluable contributions in this direction, with his great care for detail and unlimited energy. At the time of his death he was dean of the Faculty of Science and for several years had represented the Academic Board on the College Council. By his students he will probably be best remembered for the great enthusiasm that he brought to the teaching of chemistry, an enthusiasm which spared no pains to provide an interesting course and which infected his hearers with his own love of his subject. His many other duties had prevented him bringing to conclusion the researches that he started in East Africa. His earlier interest in plant alkaloids led him to investigate some of the many unknown active plant materials which have been used for years in native medicines.

'Tenniswood's death is felt no less by his colleagues than by his students. His integrity and forthrightness were appreciated in personal dealings as well as in the many boards and committees on which he served, and he had a wide range of friends both in the College and in life outside. Growing colleges such as Makerere can ill afford to lose men of Tenniswood's loyalty and calibre, and his untimely death is keenly felt by all concerned.

RALPH F. NAYLOR

\section{Dr. J. W. Fisher}

DR. J. W. FISHER, whose untimely death at the age of fifty-three was recently reported, was a member of the Royal Naval Scientific Service, having served with the Admiralty since 1939. He studied physics and mathematics in the University of London, where he obtained his Ph.D. in 1924. Having completed his postgraduate studies at Göttingen and Munich, he studied medicine and took his M.R.C.S. and L.R.C.P. and became house physician at Westminster Hospital. Before joining the Royal Naval Scientific Service he was engaged on research and exploration in Britain and in India on behalf of the Anglo-Iranian Oil Co.

While in the service of the Admiralty, Fisher's work was mainly directed to the solution of a number of highly intricate problems relating to the propagation, generation and reception of sounds in the sea. $\mathrm{H}_{e}$ brought to these problems a wide knowledge of basic physics and quite outstanding mathematical ability, coupled with the power of seeing the basic problem and to approximate-a gift which raises mathematics from a technique to a fine art. $\mathrm{H}_{\theta}$ held, with Stokes, that series solutions are devoid of elegance and showed great ingenuity in reducing his solutions to neat closed forms. The outstanding quality of his theoretical and experimental work was recognized when, in 1949 , he was awarded special merit promotion to the rank of senior principal scientific officer by the Interdepartmental scientific Panel.

Fisher had a gift for terse and pithy expression often combined with an amusing use of analogy based upon his medical experience. He had many interests apart from his scientific work, the most notable being an authoritative knowledge of antiques. $\mathrm{He}$ specialized in Chinese works of art-in particular, jade and carpets. With all this, he still found time to engage in farming on a small scale.

Men like Fisher are rare in any walk of life and his loss is much felt by his colleagues both in the Royal Naval Scientific Service and outside. 